\title{
Narrative review of the management of a relapsed clubfoot
}

\author{
Karim Masrouha ${ }^{1}$, Alice $\mathrm{Chu}^{2}$, Wallace Lehman ${ }^{1}$ \\ ${ }^{1}$ Division of Pediatric Orthopedics, Department of Orthopedic Surgery, NYU Langone Health, New York, NY, USA; ${ }^{2}$ Division of Pediatric \\ Orthopedics, Department of Orthopedic Surgery, Rutgers-New Jersey Medical School, Newark, NJ, USA \\ Contributions: (I) Conception and design: All authors; (II) Administrative support: All authors; (III) Provision of study materials or patients: A Chu, W \\ Lehman; (IV) Collection and assembly of data: All authors; (V) Data analysis and interpretation: All authors; (VI) Manuscript writing: All authors; (VII) \\ Final approval of manuscript: All authors. \\ Correspondence to: Karim Masrouha, MD. Assistant Professor, Division of Pediatric Orthopedics, Department of Orthopedic Surgery, NYU Langone \\ Orthopedic Hospital, 301 E 17 Street, Room 400f, New York, NY 10003, USA. Email: karim.masrouha@nyulangone.org.
}

\begin{abstract}
The management of idiopathic clubfoot has transformed over the past several decades as the Ponseti method for the correction of this deformity became the standard of care, and surgical release has almost all but been abandoned. The Ponseti method has shown very high initial success rate and excellent long-term functional results. Relapse of the deformity, however, continues to be a major problem, occurring in up to $40 \%$ of patient, and there is no consensus on the definition and management of the relapsed clubfoot. This review discusses the available management options for the treatment of a relapsed clubfoot deformity following initial treatment with the Ponseti method [including repeat casting, tendo-Achilles lengthening, plantar fascia release, and tibialis anterior tendon transfer (TATT)] as well as following initial surgical treatment with posteromedial release (including casting, hemiepiphysiodesis, revised posteromedial release, osteotomies, fusion, and the use of gradual distraction with external fixators). These are discussed from the least to the most invasive. Available evidence, and limitations of the literature, for the management of relapses following both the Ponseti method and initial surgical release is reviewed along with along with the reported outcomes. Future efforts should be geared towards standardizing the definition of a relapse with objective criteria for its management.
\end{abstract}

Keywords: Clubfoot; relapse; surgery; Ponseti method

Submitted Nov 30, 2020. Accepted for publication May 14, 2021.

doi: $10.21037 / \mathrm{atm}-20-7730$

View this article at: http://dx.doi.org/10.21037/atm-20-7730

\section{Introduction}

The understanding of and approach to the relapsed idiopathic clubfoot has evolved over the past few decades. Initially, the treatment of clubfoot was primarily surgical, giving rise to primarily surgical options for the treatment of relapses As the Ponseti method became more popular, the treatment of relapses transformed to reflect the noninvasive approach of the initial treatment. The objectives of this review are to discuss the identification of relapses, how to prevent them, and to synthesize the different treatment approaches to the relapsed clubfoot as a guide to the clubfoot practitioner. The review has been divided into two sections: the management of relapse following initial treatment by the Ponseti method, and, though less common over the past decade, the management of relapse following initial treatment with surgical release. We present the following article in accordance with the Narrative Review reporting checklist (available at http://dx.doi.org/10.21037/

^ ORCID: 0000-0002-3602-2215. 
Table 1 Sources and criteria used for this narrative review

PubMed search from 1970-2020 with the keywords: Clubfoot; relapse OR recurrence; treatment OR management

Research papers with cohorts of less than 10 patients were excluded

Search through the references of the retrieved manuscripts

Discussions with multiple experts in the fields

Experience of the senior authors

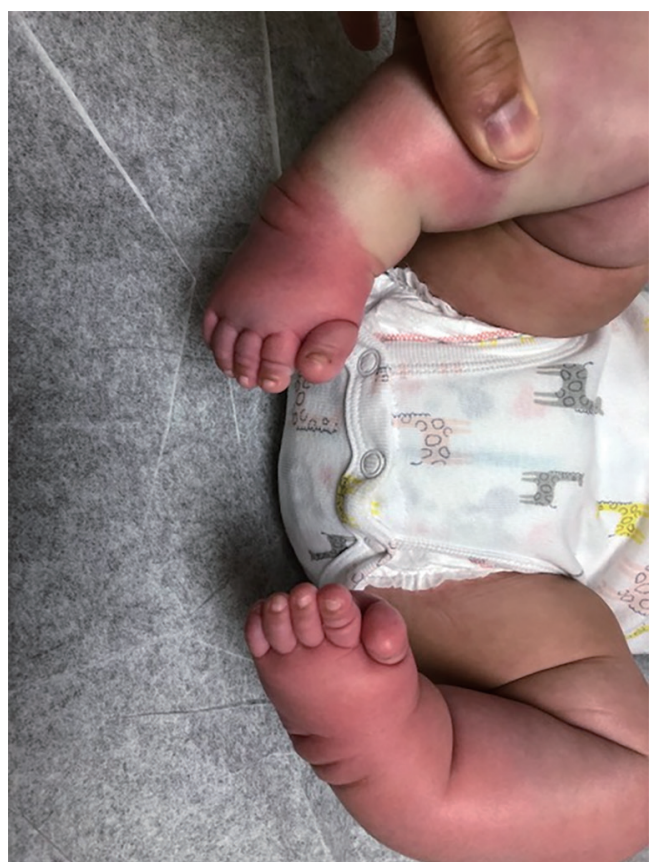

Figure 1 Clinical image of a patient with bilateral relapse of all components of the deformity.

atm-20-7730).

\section{Methods}

The sources and criteria used to write this narrative review are listed in Table 1.

\section{Relapse after treatment with Ponseti method}

The Ponseti method for the treatment of clubfoot is highly successful, with initial correction rates of over $90 \%$. There have been numerous reports in the literature discussing the rate of relapse following initial correction, which averages about $40 \%$, and is similar to those corrected with surgery, however a relapse following treatment by the Ponseti method tends to be more supple and amenable to further casting, with or without less invasive procedures, with good functional outcomes. The rate of relapse and need for further treatment, however, varies widely in the literature, partially due to deviation from the original principles set forth in the Ponseti method, but also due to a lack of consensus on the management of these patients following initial correction as well as the definition of relapse itself $(1,2)$.

Generally, relapse is defined as a presentation with any one of the clubfoot deformities, or a combination of them, after initial complete correction (Figure 1). The Pirani score is most frequently used to define a relapse (2). Despite some attempts, there is still no uniform method for defining, classifying, or predicting relapses (2-4). Equinus and adductus, in isolation or in combination, with or without dynamic supination, are the most common presentations of relapse (5). It has been well-established that non-compliance with the foot abduction orthosis (FAO) greatly increases the risk of relapse however there may be other causes such as early discontinuation of the FAO by the treating physician, soft tissue contractures, incomplete correction, or undiagnosed neuromuscular causes. This underscores the importance of parent education, support, and close, frequent follow up of patients to identify any issues with compliance early on and to modify or adjust bracing accordingly.

Though there have been many reports on techniques for the treatment of relapse after initial correction by the Ponseti method, there are no clear recommendations regarding the most appropriate treatment of these patients. These include repeat casting, repeat Achilles tenotomy, Achilles tendon lengthening, and tibialis anterior tendon transfer (TATT). In cases of relapse of clubfoot following initial complete correction by the Ponseti method, correction can be obtained without the need for extensive bony or open joint surgery (6). In this section the different treatment options from least to most invasive will be 
reviewed.

\section{Casting alone}

One of the benefits of initial treatment by the Ponseti method is that the feet are supple and are amenable to recasting without the stiffness seen in feet initially treated with extensive release. Therefore, a reasonable initial approach should be to re-cast the feet, in keeping with the principles of the Ponseti method. In a study by van Praag et al., it was found that $74 \%$ of those with a relapse were successfully treated by casting alone after a seven year follow up (7). Of note, patients with recurrence did not have a statistically significant difference in function or satisfaction compared to a control group of idiopathic clubfoot patients that did not have a relapse, based on their responses to the Disease Specific Instrument (DSI) (7). Another important finding from that study was that some patients who were brought back for evaluation for the purposes of the study after discontinuation of follow up at 5 years of age were found to have relapses (7). This underscores the importance of longer term follow up in order to diagnose and address recurrences earlier and potentially have improved success at correction with casting alone.

Re-casting following a relapse should be based on the principles of the Ponseti method and therefore should start with appropriate alignment of the forefoot, followed by abduction (or external rotation) and then correction of the equinus, if present. This will ensure that no aspect of the deformity is overlooked and, more importantly, that no iatrogenic deformity is created.

It is important to resume nighttime bracing following correction with casting. This may be challenging as the initial relapse would most likely have been due to noncompliance, but its importance must be emphasized to parents prior to initiating re-casting. Several modifications of the standard Ponseti shoes and bar may be offered to parents to potentially increase compliance. The authors have found that, in the absence of significant external barriers to compliance, the development of a recurrence is seen by parents as evidence of the importance of bracing and gives them the conviction needed to ensure it is used appropriately.

\section{Achilles tenotomy or lengthening with or without a plantar fascia release}

Some patients may present with an isolated equinus contracture that does not improve with casting or they may have residual equinus following correction of other aspects of the deformity with casting. Not infrequently, the equinus contracture may be a residual deformity due to an incomplete initial tenotomy. This is particularly true for early apparent relapses, which are more likely to be residual deformities. In younger patients, typically under the age of 2 years, an Achilles tenotomy may be indicated, while in older patients an Achilles Z-plasty lengthening can be performed. Beyond the age of 10-12 months, the tenotomy should be performed in the operating room. This is for both adequate sedation of the larger child, and to have the option of performing a mini-open tenotomy in the setting of increased scarring, which would avoid inadvertent injury to the adjacent neurovascular structures.

Frequently, there is an associated cavus deformity which accentuates the appearance of equinus. This may be corrected with a well-molded "Ponseti number one" cast, however in case there is a deep transverse plantar crease across the midfoot, the deformity should be addressed with the Ponseti cast modification for complex clubfeet (8). This is performed with gentle dorsiflexion against the metatarsal head with the thumbs, and the index fingers over the dorsum of the talar head as a fulcrum (8). If there is a persistent palpable tightness of the plantar fascia despite casting, a plantar fascia release can be performed at the time of the tenotomy with a cast placed using the abovementioned technique (9).

\section{TATT}

The TATT is one of the most commonly performed procedures for the correction of recurrence following correction by the Ponseti method. The most commonly reported indication to perform a TATT is dynamic supination seen during the swing phase of gait (Figure 2). This is frequently seen in association with an equinus contracture, and therefore an Achilles tendon lengthening or gastrocnemius recession (Strayer procedure) is performed at the same time of the transfer. In a review of 39 patients that relapsed after the age of 4 years following complete initial correction by the Ponseti method, almost all required a TATT, whether initially or after casting and bracing (10). In a more recent study of 101 patients who had very poor compliance with the bracing protocol, resulting in a $68 \%$ relapse rate, $38 \%$ underwent a TATT. Yet despite the high relapse rate the majority reported a good functional outcome and were satisfied with the appearance of the 


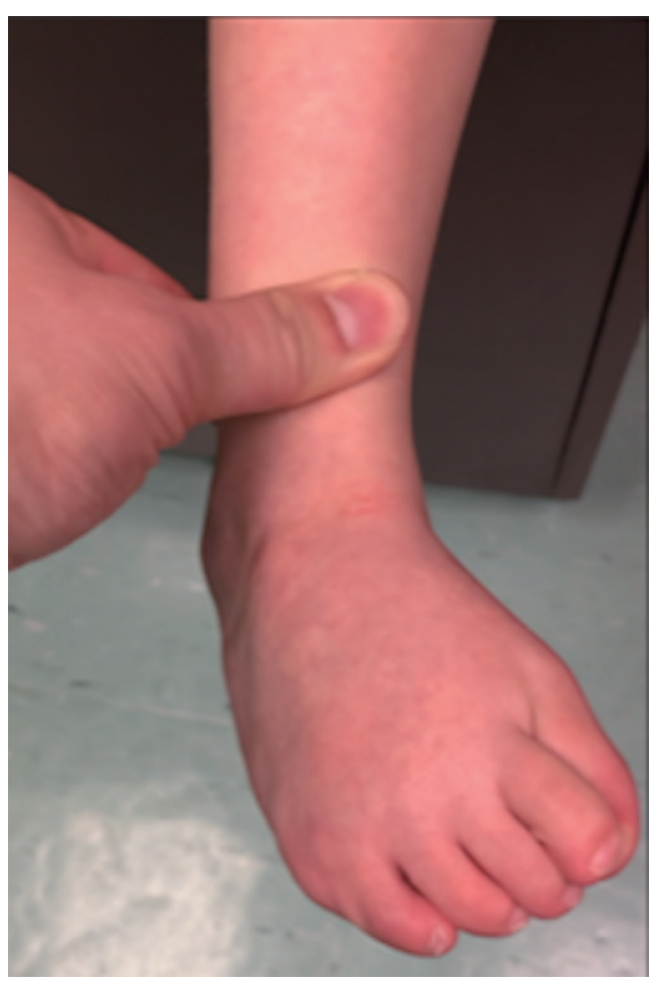

Figure 2 Clinical image of the right foot of a child demonstrating dynamic supination with attempted ankle dorsiflexion.

foot (11). It should be noted, however, that approximately $15 \%$ of patients may develop a second relapse following a TATT (12). The reasons may include performing the transfer prior to adequate ossification of the lateral cuneiform or due to underlying undiagnosed neuromuscular disorders.

A prerequisite to performing a TATT is to have a supple foot that only dynamically supinates but is otherwise passively correctable. This does not guarantee that a transfer is needed, though, as some patients may present with dynamic supination, however once the foot is appropriately aligned with casting, the child may actively dorsiflex without supination, obviating the need for a transfer. Another mistake that can be made is to perform a TATT in a patient with metatarsus adductus. This will not realign the foot and the parents and patient will not be satisfied with the appearance or functional outcome following the transfer. Therefore, attempting to correct the deformity with casting first and re-assessing the foot prior to indicating for surgery is the most appropriate approach. It must be noted that the indications for a TATT are not well defined in the literature or in any of the cited studies above.
Following a TATT, patients are generally placed in a long leg cast for a period of 6 weeks without weight bearing. There is no consensus regarding bracing following cast removal but the authors recommend the use of a custom ankle-foot orthosis for a period of approximately 6 months.

In summary, this section has reviewed the treatment options for relapse following the treatment of idiopathic clubfoot by the Ponseti method. Generally, the functional outcome and satisfaction of these patients is favorable. The key is to understand the deformity and to re-cast accordingly, in addition to ensuring close, frequent follow up and educating the parents and child on continuing a nighttime FAO following adequate correction for an appropriate amount of time. There may be some patients that require surgical correction, but these almost never require invasive intra-articular or bony surgery, and are limited to tenotomies, tendon lengthening, fascial release, or tendon transfers. Those that potentially may need more aggressive surgery include older patients with neglected deformities or non-idiopathic clubfeet. These surgeries are the same as those for the treatment of relapse following initial surgical correction, discussed below. The main pitfall of the literature is that almost all of the data is from poor quality studies without adequate follow up, therefore it is difficult to make clear recommendations. Future goals should be to conduct studies to better define relapses, determine the adequate duration of nighttime FAO use, and provide a systematic approach to the management of relapses.

\section{Relapse after surgery}

What is the difference between relapse after the Ponseti method, compared with after posteromedial release? Ippolito et al. compared these two groups with a follow up of almost twenty years (13). In both groups, the rate of relapse occurred in $41-47 \%$ of cases, but functional outcomes in the Ponseti group were much better (13). Of note, nine relapsed feet in the first group required revision releases, of which $6(66 \%)$ had a second relapse (Figure 3). Clarke et al. have also found no difference in rate of relapse between patients treated with the Ponseti method (32\%) versus operative release (31\%) (14). Despite the high relapse rate, clubfeet treated with the Ponseti method tend to function better and require less invasive forms of further treatment $(15,16)$.

Clubfeet that have been treated with posteromedial release understandably have extensive scarring. Although 

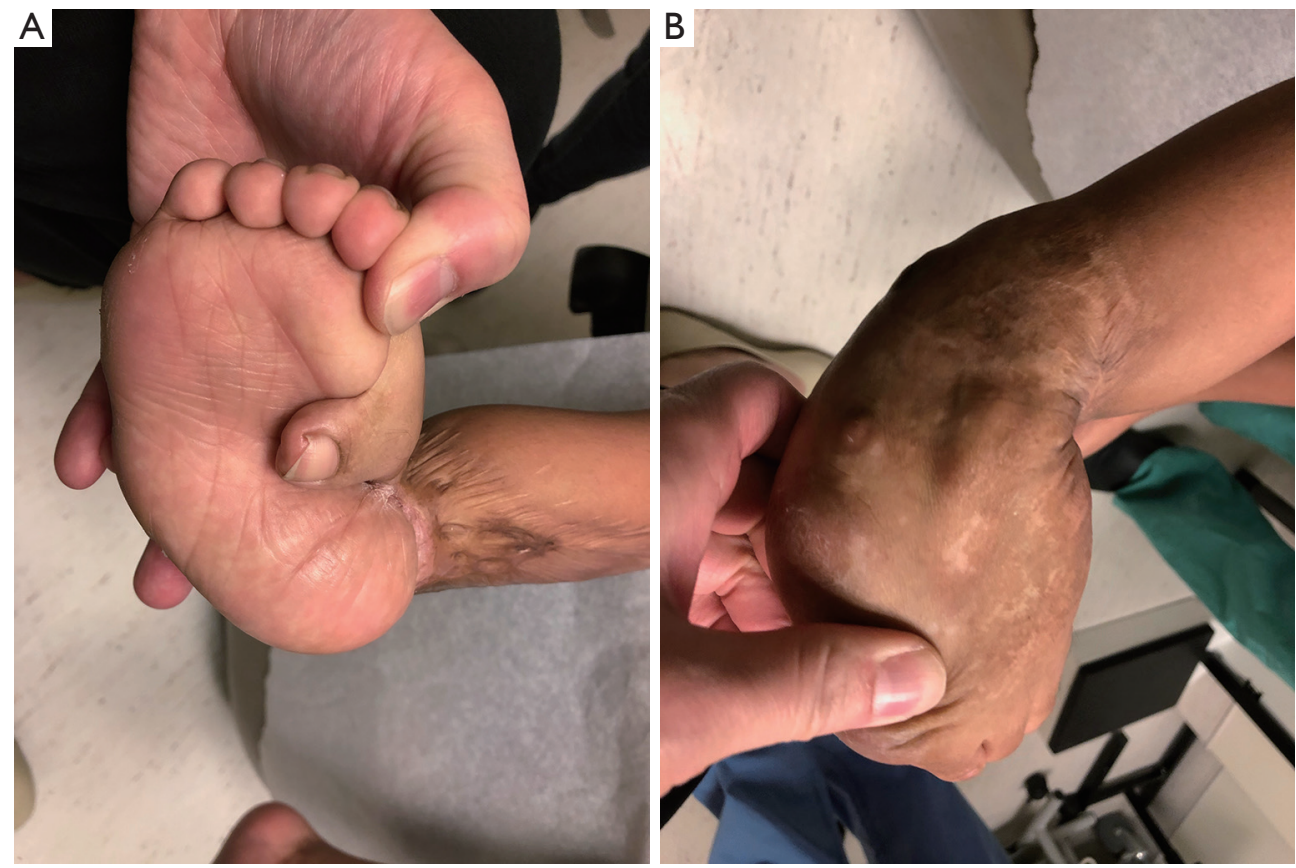

Figure 3 Clinical images of the (A) medial and (B) lateral aspects of the right foot of a patient who relapsed following extensive surgical release.

their incidence may be decreasing overall, these cases still present on occasion $(9,17,18)$. There are many factors that render these feet at high risk when undergoing further correction. First, the vasculature may have been damaged from the original surgery, leading to compromised perfusion of the foot, and a higher risk of subsequent gangrene or amputation. Secondly, joint spaces which have been opened will likely have pre-arthritic changes, and are less supple during attempted movement. Finally, the overlying skin is often scarred and fibrotic, making wound closure difficult. Traditionally, these cases are some of the most difficult ever encountered by pediatric orthopaedists.

Nogueira et al. wrote about an innovative application of the Ponseti method in correcting recurrent clubfoot following failed posteromedial release (19). With a follow up of 2 years, the authors obtained $86 \%$ plantigrade/fully corrected feet, with the remaining $14 \%$ having a second recurrence (19). Because of the relatively low risk of the Ponseti method, this should likely be the first treatment offered in cases of recurrent clubfoot. The major downside to this approach is that it may be successful in only some cases $(20,21)$.

There are also select patients where the deformity can be isolated to a certain anatomic location, such as the distal tibia or the midfoot. Anterior hemi-epiphysiodesis of the distal tibia may be utilized to treat residual equinus. Ebert et al. showed improvement of dorsiflexion through change in the anterior distal tibial angle after placement of 8-plates (22). However, follow up was scant and it is unclear whether relapse or arthritic changes may occur due to changing the morphology of the tibiotalar joint. Al-Aubaidi et al. also showed little change in clinical dorsiflexion despite changing the anterior distal tibial angle (23). For cases of midfoot deformity, lateral column fusion can effectively tether further growth. Mid- and long-term follow-up after revision posteromedial release in combination with calcaneocuboid fusion, have shown maintenance of a straight lateral border of the foot without over-correction $(24,25)$.

The a la carte approach described by Bensahel aims to deconstruct the relapsed clubfoot deformity into pieces which can be individually addressed (26). Mubarak et al. described navicular excision and cuboid osteotomy to specifically correct cavus midfoot deformity, and all patients had a plantigrade foot at a follow-up of 5 years (27). Similarly, Lourenco at al. reported successful closing wedge cuboid and opening wedge medial cuneiform osteotomies for residual adductus deformity, again with good maintenance at nearly 5 years follow-up (28). Eidelman 

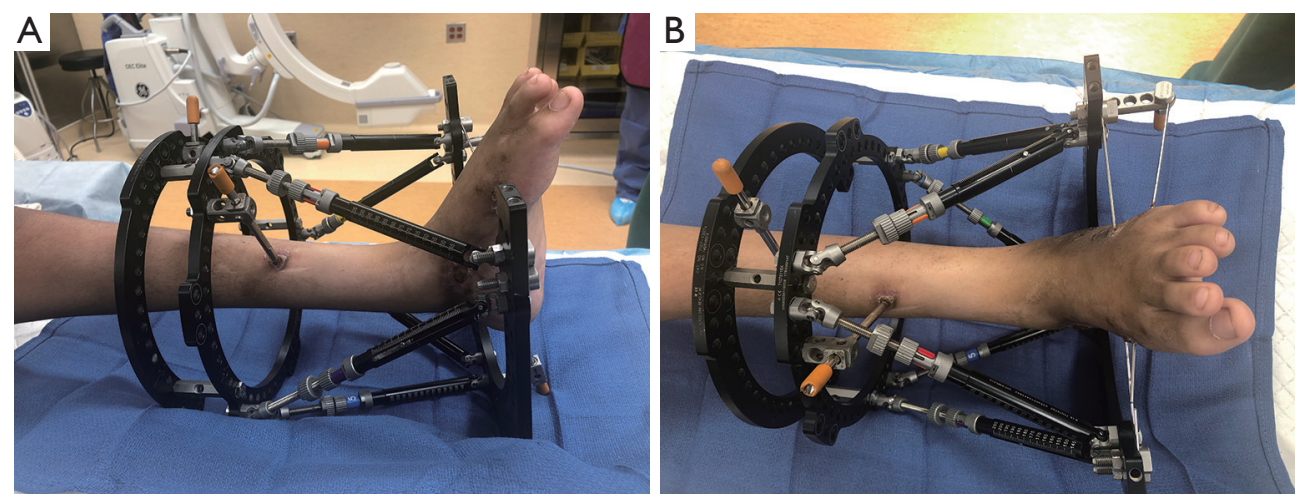

Figure 4 (A) Sagittal and (B) coronal clinical images of the left foot of a patient who underwent gradual corrections using a hexapod frame.

et al. performed a percutaneous midfoot osteotomy and gradual correction using a Taylor spatial frame (called the "Butt" frame due to the U-plate aligned parallel to the plantar aspect of the foot) in children with an average age of 14.7 years (29). In addition to midfoot osteotomies, patients with mild hindfoot deformity may have a calcaneal osteotomy (30,31). Wicart and Seringe reported satisfactory results in a group of mostly neurologic patients using cuneiform and calcaneal osteotomies (32).

In the most severe relapsed clubfeet, repeat soft tissue releases are required to correct the significant midfoot and hindfoot deformities. There are some variations in this procedure, but they can generally be divided into acute or gradual correction. In cases fixed acutely, soft tissue complications are likely to occur, and collaboration with plastic surgery should be considered. Furthermore, these surgeries may require bone osteotomies in addition to the soft tissue work. Silver $e t a l$. have described the use of preoperative tissue expansion, while other authors have utilized regional, local, or cross-leg fasciocutaneous flaps (33-35). Mehrafshan described use of calcaneal excision and Souchet used calcaneal derotational osteotomies in combination with repeat posteromedial releases $(36,37)$.

Gradual correction using an external fixator, most commonly an Ilizarov frame, can avoid problems with wound closure (38) (Figure 4). However, placement of multiplanar external fixators is technically challenging, and the extended immobilization period may predispose patients to post-operative stiffness. Many authors have been successful in correcting relapsed clubfeet using soft tissue distraction and Ilizarov-type frames $(39,40)$. In a novel approach, Tripathy et al. placed Ilizarov frames and applied gradual correction with the Ponseti sequence, using two stages of frame construction (41). Stage 1, correction of the midfoot, preceded stage 2, application and correction with the hindfoot frame. Eidelman et al. named this method the "Ponse-Taylor" strategy in honor of Dr. Ponseti and Dr. Taylor (of the Taylor Spatial frame) (9). Khanfour noted that older children, described as $8-13$ years of age, would require adjunctive osteotomies using the Ilizarov technique (42).

Finally, the most severe cases of recurrent clubfoot may be treated by osteotomies and fusions. As a last resort, triple arthrodesis may be utilized but is best reserved for older patients. Galindo et al. performed triple arthrodesis after failed clubfoot soft tissue releases in patients with an average age of 8.4 years (43). Long-term follow-up data is lacking for this type of surgery in children, and the expected prognosis is poor. The Lambrinudi osteotomy consists of bone resection from the talus, navicular and calcaneus for the treatment of severe equinus. So et al. reported fair to good outcomes in a cohort of mostly polio patients, at a follow up of 37 years (44). Spires et al. have also performed the Verbelyi-Ogston procedure, subchondral excision of the talus and cuboid, in patients with clubfeet secondary to myelomeningocele or arthrogryposis (45).

In summary, this section has reviewed the treatment of relapsed clubfoot after posteromedial release in the order of least to most invasive. The difficulty and high risks of these surgeries, in combination with increased stiffness experienced by patients, have been the major reasons why posteromedial release has fallen out of favor in lieu of less invasive treatments (46). Some authors have been very successful in using the Ponseti method for these cases, but whether it can be tolerated or performed in all patients is as yet uncertain. Fortunately, clubfoot patients are increasingly being treated nonoperatively, so the frequency of relapse after posteromedial release has likely decreased. The 
present rarity of these cases would suggest that these should be treated by centers or practitioners with the capability to perform a wide variety of surgical techniques. Additionally, it is unlikely that further research will be conducted on these patients as the Ponseti method is the standard treatment practiced throughout the world.

\section{Acknowledgments}

Funding: None.

\section{Footnote}

Provenance and Peer Review: This article was commissioned by the Guest Editors (Federico Canavese and Alain Dimeglio) for the series "Clubfoot" published in Annals of Translational Medicine. The article has undergone external peer review.

Reporting Checklist: The authors have completed the Narrative Review reporting checklist. Available at http:// dx.doi.org/10.21037/atm-20-7730

Conflicts of Interest: All authors have completed the ICMJE uniform disclosure form (available at http://dx.doi. org/10.21037/atm-20-7730). The series "Clubfoot" was commissioned by the editorial office without any funding or sponsorship. The authors have no other conflicts of interest to declare.

Ethical Statement: The authors are accountable for all aspects of the work in ensuring that questions related to the accuracy or integrity of any part of the work are appropriately investigated and resolved.

Open Access Statement: This is an Open Access article distributed in accordance with the Creative Commons Attribution-NonCommercial-NoDerivs 4.0 International License (CC BY-NC-ND 4.0), which permits the noncommercial replication and distribution of the article with the strict proviso that no changes or edits are made and the original work is properly cited (including links to both the formal publication through the relevant DOI and the license). See: https://creativecommons.org/licenses/by-nc-nd/4.0/.

\section{References}

1. Zhao D, Liu J, Zhao L, et al. Relapse of clubfoot after treatment with the Ponseti method and the function of the foot abduction orthosis. Clin Orthop Surg 2014;6:245-52.

2. Gelfer $\mathrm{Y}$, Wientroub S, Hughes K, et al. Congenital talipes equinovarus: a systematic review of relapse as a primary outcome of the Ponseti method. Bone Joint J 2019;101B:639-45.

3. Zhao D, Li H, Zhao L, et al. Prognosticating Factors of Relapse in Clubfoot Management by Ponseti Method. J Pediatr Orthop 2018;38:514-20.

4. Bhaskar A, Patni P. Classification of relapse pattern in clubfoot treated with Ponseti technique. Indian J Orthop 2013;47:370-6.

5. Chand S, Mehtani A, Sud A, et al. Relapse following use of Ponseti method in idiopathic clubfoot. J Child Orthop 2018;12:566-74.

6. Radler C, Mindler GT, Riedl K, et al. Midterm results of the Ponseti method in the treatment of congenital clubfoot. Int Orthop 2013;37:1827-31.

7. van Praag VM, Lysenko M, Harvey B, et al. Casting Is Effective for Recurrence Following Ponseti Treatment of Clubfoot. J Bone Joint Surg Am 2018;100:1001-8.

8. Ponseti IV, Zhivkov M, Davis N, et al. Treatment of the complex idiopathic clubfoot. Clin Orthop Relat Res 2006;451:171-6.

9. Eidelman M, Kotlarsky P, Herzenberg JE. Treatment of relapsed, residual and neglected clubfoot: adjunctive surgery. J Child Orthop 2019;13:293-303.

10. McKay SD, Dolan LA, Morcuende JA. Treatment results of late-relapsing idiopathic clubfoot previously treated with the Ponseti method. J Pediatr Orthop 2012;32:406-11.

11. Zionts LE, Ebramzadeh E, Morgan RD, et al. Sixty Years On: Ponseti Method for Clubfoot Treatment Produces High Satisfaction Despite Inherent Tendency to Relapse. J Bone Joint Surg Am 2018;100:721-8.

12. Masrouha KZ, Morcuende JA. Relapse after tibialis anterior tendon transfer in idiopathic clubfoot treated by the Ponseti method. J Pediatr Orthop 2012;32:81-4.

13. Ippolito E, Farsetti P, Caterini R, et al. Long-term comparative results in patients with congenital clubfoot treated with two different protocols. J Bone Joint Surg Am 2003;85:1286-94.

14. Clarke NM, Uglow MG, Valentine KM. Comparison of Ponseti versus surgical treatment in congenital talipes equinovarus. J Foot Ankle Surg 2011;50:529-34.

15. Halanski MA, Davison JE, Huang JC, et al. Ponseti method compared with surgical treatment of clubfoot: 
a prospective comparison. J Bone Joint Surg Am 2010;92:270-8.

16. Zapata KA, Karol LA, Jeans KA, et al. Gross Motor Function at 10 Years of Age in Children With Clubfoot Following the French Physical Therapy Method and the Ponseti Technique. J Pediatr Orthop 2018;38:e519-e523.

17. Radler C, Mindler GT. Treatment of Severe Recurrent Clubfoot. Foot Ankle Clin 2015;20:563-86.

18. Penny JN. The neglected clubfoot. Tech Orthop 2005;20:153-66.

19. Nogueira MP, Ey Batlle AM, Alves CG. Is it possible to treat recurrent clubfoot with the Ponseti technique after posteromedial release?: a preliminary study. Clin Orthop Relat Res 2009;467:1298-305.

20. Chu A, Lehman WB. Treatment of Idiopathic Clubfoot in the Ponseti Era and Beyond. Foot Ankle Clin 2015;20:555-62.

21. Garg S, Dobbs MB. Use of the Ponseti method for recurrent clubfoot following posteromedial release. Indian J Orthop 2008;42:68-72.

22. Ebert N, Ballhause TM, Babin K, et al. Correction of Recurrent Equinus Deformity in Surgically Treated Clubfeet by Anterior Distal Tibial Hemiepiphysiodesis. J Pediatr Orthop 2020;40:520-5.

23. Al-Aubaidi Z, Lundgaard B, Pedersen NW. Anterior distal tibial epiphysiodesis for the treatment of recurrent equinus deformity after surgical treatment of clubfeet. J Pediatr Orthop 2011;31:716-20.

24. Lehman WB, Atar D, Bash J, et al. Results of complete soft tissue clubfoot release combined with calcaneocuboid fusion in the 4-year to 8-year age group following failed clubfoot release. J Pediatr Orthop B 1999;8:181-6.

25. Chu A, Chaudhry S, Sala DA, et al. Calcaneocuboid arthrodesis for recurrent clubfeet: what is the outcome at 17-year follow-up? J Child Orthop 2014;8:43-8.

26. Bensahel H, Csukonyi Z, Desgrippes Y. Surgery in residual clubfoot: one-stage medioposterior release "a la carte". J Pediatr Orthop 1987;7:145-8.

27. Mubarak SJ, Dimeglio A. Navicular excision and cuboid closing wedge for severe cavovarus foot deformities: a salvage procedure. J Pediatr Orthop 2011;31:551-6.

28. Lourenco AF, Dias LS, Zoellick DM, et al. Treatment of residual adduction deformity in clubfoot: the double osteotomy. J Pediatr Orthop 2001;21:713-8.

29. Eidelman M, Keren Y, Katzman A. Correction of residual clubfoot deformities in older children using the Taylor spatial butt frame and midfoot Gigli saw osteotomy. J
Pediatr Orthop 2012;32:527-33.

30. Rathjen KE, Mubarak SJ. Calcaneal-cuboid-cuneiform osteotomy for the correction of valgus foot deformities in children. J Pediatr Orthop 1998;18:775-82.

31. Koutsogiannis E. Treatment of mobile flat foot by displacement osteotomy of the calcaneus. J Bone Joint Surg Br 1971;53:96-100.

32. Wicart P, Seringe R. Plantar opening-wedge osteotomy of cuneiform bones combined with selective plantar release and dwyer osteotomy for pes cavovarus in children. $J$ Pediatr Orthop 2006;26:100-8.

33. Silver L, Grant AD, Atar D, et al. Use of tissue expansion in clubfoot surgery. Foot Ankle 1993;14:117-22.

34. Lubicky JP, Altiok H. Regional fasciocutaneous flap closure for clubfoot surgery. J Pediatr Orthop 2001;21:50-4.

35. Hassan FO, Jabaiti S, El tamimi T. Complete subtalar release for older children who had recurrent clubfoot deformity. Foot Ankle Surg 2010;16:38-44.

36. Mehrafshan M, Rampal V, Seringe R, et al. Recurrent club-foot deformity following previous soft-tissue release: mid-term outcome after revision surgery. J Bone Joint Surg Br 2009;91:949-54.

37. Souchet P, Ilharreborde B, Fitoussi F, et al. Calcaneal derotation osteotomy for clubfoot revision surgery. J Pediatr Orthop B 2007;16:209-13.

38. Grill F, Franke J. The Ilizarov distractor for the correction of relapsed or neglected clubfoot. J Bone Joint Surg Br 1987;69:593-7.

39. Gupta P, Bither N. Ilizarov in relapsed clubfoot: a necessary evil? J Pediatr Orthop B 2013;22:589-94.

40. El-Sayed M. Ilizarov external fixation for management of severe relapsed clubfeet in older children. Foot Ankle Surg 2013;19:177-81.

41. Tripathy SK, Saini R, Sudes P, et al. Application of the Ponseti principle for deformity correction in neglected and relapsed clubfoot using the Ilizarov fixator. J Pediatr Orthop B 2011;20:26-32.

42. Khanfour AA. Ilizarov techniques with limited adjunctive surgical procedures for the treatment of preadolescent recurrent or neglected clubfeet. J Pediatr Orthop B 2013;22:240-8.

43. Galindo MJ Jr, Siff SJ, Butler JE, et al. Triple arthrodesis in young children: a salvage procedure after failed releases in severely affected feet. Foot Ankle 1987;7:319-25.

44. So LWN, Kuong EE, To KM, et al. Long-term outcome after Lambrinudi arthrodesis: How they're 
doing after three decades. J Orthop Surg (Hong Kong) 2019;27:2309499019826492.

45. Spires TD, Gross RH, Low W, et al. Management of the resistant myelodysplastic or arthrogrypotic clubfoot with the Verebelyi-Ogston procedure. J Pediatr Orthop

Cite this article as: Masrouha $\mathrm{K}$, Chu $\mathrm{A}$, Lehman W. Narrative review of the management of a relapsed clubfoot. Ann Transl Med 2021;9(13):1102. doi: 10.21037/atm-20-7730
1984:4:705-10.

46. Zionts LE, Zhao G, Hitchcock K, et al. Has the rate of extensive surgery to treat idiopathic clubfoot declined in the United States? J Bone Joint Surg Am 2010;92:882-9. 